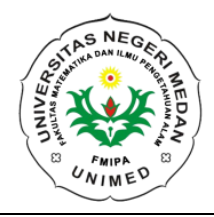

\author{
JURNAL EINSTEIN \\ Jurnal Hasil Penelitian Bindang Fisika \\ Available online http://jurnal.unimed.ac.id/2012/index.php/einsten \\ e-issn: $2407-747 x$, p-issn $2338-1981$
}

\title{
SIMULASI SISTEM SUSPENSI MOBIL MENGGUNAKAN MAGNETORHEOLOGICAL SEBAGAI PEREDAM
}

\author{
Ester Ikalia Halawa dan Jonny H. Panggabean \\ Jurusan Fisika, Fakultas Matematika dan Ilmu Pengetahuan Alam, Universitas Negeri Medan, \\ Indonesia \\ esterikalia@mhs.unimed.ac.id \\ Diterima September 2018; Disetujui Oktober 2018; Dipublikasikan November 2018
}

\begin{abstract}
ABSTRAK
Sistem simulasi suspensi mobil menggunakan magnetorheological sebagai peredam bertujuan untuk mengetahui nilai kekakuan pegas mobil, program simulasi, grafik bentuk redaman pada suspensi mobil serta membandingkan redaman mobil sebelum dan sesudah menggunakan magnetorheological sebagai peredam. Dalam merancang sistem suspensi tersebut terdapat dua tahapan, yaitu tahap perancangan dan tahap analisis. Pada tahap perancangan dilakukan perhitungan dan simulasi untuk mendapatkan nilai konstanta pegas suspensi. Tahap analisa dilakukan analisa kenyamanan sistem suspensi yang menggunakan standar ISO 2631, berdasarkan VDV dan percepatan RMS. Hasil yang diperoleh adalah nilai kekakuan redaman suspensi yang menggunakan peredam magnetorheological sebesar $7.540 .547,73 \mathrm{~N} / \mathrm{ms}$ dengan nilai VDV $1,568 \mathrm{~m} / \mathrm{s}^{1.75}$ dan nilai percepatan RMS sebesar $0,315 \mathrm{~m} / \mathrm{s}^{2}$. Hasil analisisberdasarkan standart keamanan dan kenyamanan nilai suspensi yang telah dirancang memiliki tingkat keamanan dan kenyamanan yang baik.
\end{abstract}

Kata Kunci : Sistem suspensi, peredam magnetorheological, ISO 2631

\section{PENDAHULUAN}

Perkembangan teknologi otomotif dewasa ini sangat pesat. Kenyamanan dan keamanan pengendara menjadi faktor yang paling utama disamping kehandalan dari suatu mesin, misalnya mobil. Hal ini mendorong industri-industri otomotif bersaing untuk menghasilkan suatu produk otomotif yang berkualitas. Kenyamanan dan keselamatan pengendara atau penumpang kendaraan bermotor khususnya kendaraan roda empat harus terjamin baik secara langsung maupun tidak langsung.

Sistem suspensi kendaraan, khususnya mobil, dalam hal ini dilakukan sebagai pengontrolan, yang mana objektifnya adalah untuk kenyamanan bagi pengendara, sewaktu membawa mobil dijalan yang tidak rata (rusak). Sistem yang digunakan dalam hal ini adalah sistem suspensi semi aktif, yang mana konstanta pegas (spring) dan damper bisa dirubah seketika.

Solusi-solusi untuk memeperbaiki kinerja peredam suspensi mobil telah banyak dirancang dan dilakukan. Ilmu pengetahuan terbaru kini adalah sedang dirancangnya modifikasi peredam untuk suspensi pada mobil menggunakan suatu cairan sebagai peredam. Cairan peredam ini disebut Magnetorheological Fluid.

Penelitian ini menggunakan mobil pickup Mitsubishi L300 sebagai subjek untuk data penelitian. Hal ini dikarenakan penggunaan mobil pick-up Mitsubishi L300 sering menjadi andalan masyarakat sebagai transportasi 
pengangkutan barang. Selain modelnya yang simpel, mobil pick-up Mitsubishi L300 juga memiliki bak penampungan barang yang cukup besar, serta harga per mobilnya yang dapat dijangkau.

Adapun tujuan dilakukannya penelitian ini adalah untuk mengetahui nilai kekakuan pegas mobil, bentuk simulasi dan grafik redaman suspensi yang menggunakan magnetorheological sebagai peredam pada suspensi seperempat kendaraan, serta mengetahui perbandingan redaman yang menggunakan dan yang tidak menggunakan magnetorheological sebagai peredam.

\section{METODE PENLITIAN}

\section{Alat dan Bahan}

Alat yag digunakan dalam peelitian ini adalah laptop dengan spesifikasi Asus $\mathrm{X} 44 \mathrm{H}$ dan bahan yang digunakan adalah literatur mobil pick-up Mitsubishi L300, software Matlab dan software Microsoft Excel.

\section{Tahap Penelitian}

Pada penelitian ini terdapat 2 tahap, yaitu tahap perancangan dan tahap analisis. Pada tahap perancangan dilakukan perhitungan dan simulasi untuk mendapatkan nilai konstanta pegas suspensi. Pada tahap analisa, dilakukan analisa kenyamanan yang dihasilkan sistem suspensi yang sudah dirancang dengan menggunakan standar kenyamanan dan keamanan ISO 2631, serta membandingkan bentuk grafik redaman yang dihasilkan oleh simulasi suspensi yang menggunakan dan yang tidak menggunakan magnetor-heological sebagai peredam.

\section{A. Studi Literatur dan Pengumpulan Data}

Penelitian ini diawali dengan melakukan studi literatur serta pengumpulan data. Pada tahap ini dilakukan pengumpulan literatur berupa buku serta jurnal yang dapat mendukung penelitian tugas akhir ini. Selain itu juga dilakukan pengumpulan data spesifikasi mobil dari bererapa katalog serta datasheet terkait kendaraan yang dianalisa.

\section{B. Perhitungan data}

Dengan menggunakan data spesifikasi kendaraan pick-up Mitsubishi Colt L300, maka dapat dilakukan perhitungan untuk mengetahui nilai massa sprung, koefisien per sprung, koefisien per unsprung dan koefisien redaman peredam kejut.

\section{Lintasan permukaan jalan}

Penggunaan strategi control sky-hook untuk sistem suspensi dengan gain kontrol yang dilakukan secara iterasi logaritmik dengan range 0.01 - 10 dengan uji profil jalan dengan amplitudo $10 \mathrm{~cm}$ seperti pada gambar1.

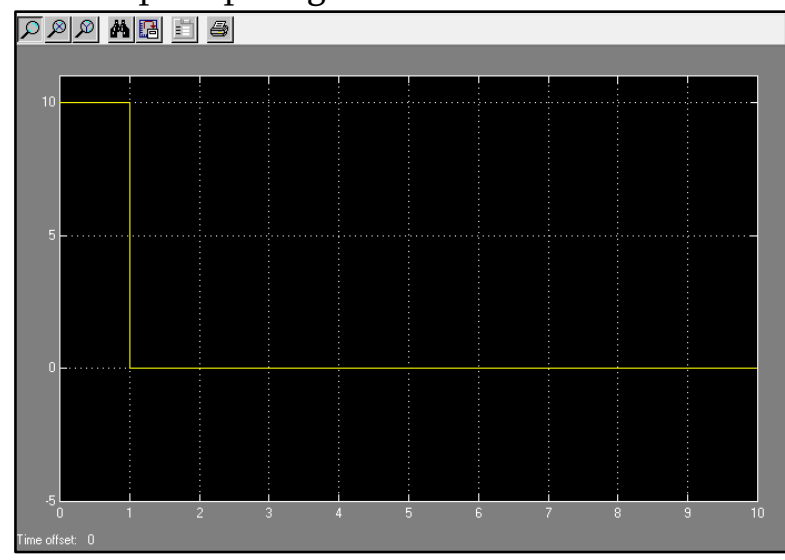

Gambar 1. Lintasan permukaan jalan

\section{Model suspensi quarter-car}

Berikut adalah model suspensi quartercaryang akan digunakan :

1. Model suspensi tanpa menggunakan magnetorheological sebagai peredam.

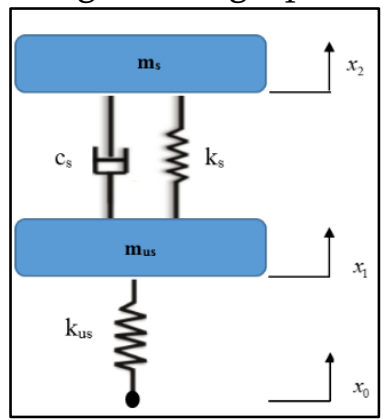

Gambar 2. Model suspensi quarter-car tanpa menggunakan magnetor-heological sebagai peredam

2. Model suspensi menggunakan magnetorheological sebagai peredam.

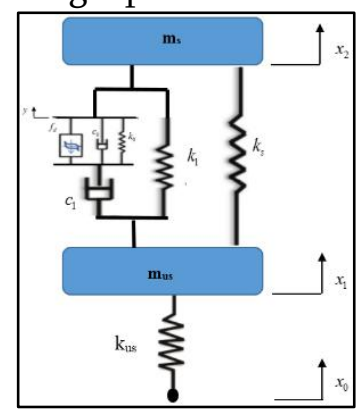


Gambar 3. Model suspensi quarter-car yang menggunakan magnetorheological sebagai peredam

\section{E. Skema Simulink}

Untuk mengetahui konstanta peredam baru yang menggunakan magne-torheological sebagai peredam dapat dihitung dengan menggunakan simulink pada Matlab.

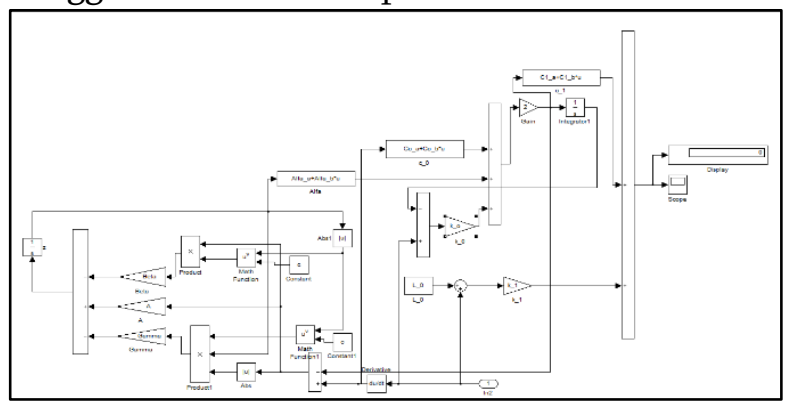

Gambar 4. Skema simulink pada Matlab

\section{F. Metode State-Space}

Bentuk umum metode State-Space

$$
\begin{aligned}
& \dot{X}=A x+B u \\
& Y=C x+D u
\end{aligned}
$$

dimana adalah vektor state, $\mathrm{A}$ adalah maktriks state, B adalah matriks input, $\mathrm{Y}$ adalah vektor input, $\mathrm{C}$ adalah matriks output, $\mathrm{D}$ adalah matriks transmisi langsung dan $\mathrm{u}$ adalah vektor output.

\section{G. Program Simulasi}

Berdaarkan metode state-space tersebut, berikut adalah program yang digunakan untuk menentukan redaman pada sistem suspensi quarter-car tanpa menggunakan magnetorheological sebagai peredam.

$$
\begin{aligned}
& \text { \%Input } \\
& \text { ms }=; \% \text { massa sprung } \\
& \text { mus }=; \% \text { massa unsprung } \\
& \text { ks }=; \% \text { koefisien per sprung } \\
& \text { kus }=; \% \text { koefisien per unsprung } \\
& \mathrm{cs}=; \% \text { koefisien redaman sprung } \\
& \text { \%Proses }
\end{aligned}
$$

$\mathrm{A}=[-\mathrm{cs} / \mathrm{ms} \mathrm{cs} / \mathrm{ms}-\mathrm{ks} / \mathrm{ms} 0 ; \mathrm{cs} / \mathrm{mus}-$

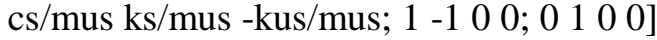

$\mathrm{B}=[-1 / \mathrm{ms} ; 1 / \mathrm{mus} ; 0 ; 0]$

$\mathrm{C}=\left[\begin{array}{llll}0 & 0 & 0 & 1\end{array}\right] \%$ posisi

$\mathrm{C} 1=\left[\begin{array}{llll}0 & 0 & 1 & 0\end{array}\right] \%$ kecepatan

$\mathrm{C} 2=\left[\begin{array}{llll}1 & -1 & 0 & 0\end{array}\right] \%$ percepatan

$\mathrm{D}=[0]$

$t=0: 0.01: 50$;

$u=0.1 *$ ones $(\operatorname{size}(t))$;

$\%$ Output

$[Y, X]=l \operatorname{sim}(A, B, C, C 1, C 2, D, u, t)$;

$y_{-} \max =\max ([Y, X])$;

$$
y_{-} \min =\min ([Y, X]) \text {; }
$$

\section{$\mathrm{H}$. Analisis keamanan dan kenyamanan}

ISO adalah internasional untuk standarisasi (Internasional Organization for Standardization). Analisis keamanan dan kenyamanan sistem suspesi digunakan standart ISO 2631. ISO 2631 merupakan standart yang menunjukkan standart tingkat resiko paparan getaran berdasarkan nilai percepatan getaran dan nilai value dose vibration (VDB). Nilai percepatan getaran dihitung dengan metode root mean square (r.m.s) dan digunakan sebagai kriteria untuk mengukur tingkat resiko yang disebabkan oleh getaran yang bersifat stabil dan terusmenerus. Sedangkan nilai value dose vibration (VDB) digunakan sebagai ukuran untuk mengukur getaran yang bersifat benturan seketika.

Untuk menghitung nilai VDV dan percepatan RMS digunakan persamaan beritut:

$$
\begin{aligned}
& V D V=\left(\int_{0}^{T}\left[a_{w}(t)\right]^{4} d t\right)^{1 / 4} \\
& a_{r . m . s .}=\left(\frac{1}{T} \int_{0}^{T}\left[a_{w}(t)\right]^{2} d t\right)^{1 / 2}
\end{aligned}
$$

Persepsi dan tingkat kenyamanan berdasarkan ISO 2631 dapat dilihat pada tabel 1 dan 2

Tabel 1. Nilai VDV dan tingkat kenyamanan

$$
\text { VDV Persepsi dan Tingkat }
$$

$\left[\mathrm{m} /\right.$ detik $\left.^{1.75}\right] \quad$ Kenyamanan

$<0,660 \quad$ Nyaman (Not uncomfortable)

0,660-2,380 Terganggu (Disturbing)

2,380 - 4,640 Tidak dapat diterima (Unacceptable)

Kemungkinan timbul

> 4,640 kepanikan (Probably causing panic)

Tabel 2. Nilai RMS dan tingkat kenyamanan

\begin{tabular}{cc}
\hline r.m.s. \\
{$\left[\mathbf{m} /\right.$ detik $\left.^{2}\right]$} & $\begin{array}{c}\text { Persepsi dan Tingkat } \\
\text { Kenyamanan }\end{array}$ \\
\hline$<0,315$ & Nyaman \\
$0,315-0,63$ & Sedikit tidak nyaman \\
$0,5-1$ & Cukup tidak nyaman \\
$0,8-1,6$ & Tidak nyaman \\
$1,25-2,5$ & Sangat tidak nyaman \\
$>2$ & Ekstrim tidak nyaman \\
\hline
\end{tabular}

\section{HASIL DAN PEMBAHASAN}

Adapun hasil yang didapat pada penelitian ini adalah:

\section{Hasil perhitungan sistem suspensi}

Massa sprung (ms) 
Massa mobil yang digunakan adalah $1 / 4$ kendaraan. Maka, nilai massa $1 / 4$ kendaraan adalah :

Massa $1 / 4=\frac{\text { Massa total kendaraan kosong }}{4}$

Massa $1 / 4=\frac{1165 \mathrm{~kg}}{4}=291,25 \mathrm{~kg}$

Maka, $\quad m_{s}=(\operatorname{massa} 1 / 4-$ massa unsprung $)=$ $291,25 \mathrm{~kg}-10 \mathrm{~kg}=281,25 \mathrm{~kg}$.

Koefisien per sprung (ks)

Mobil Pick-up Mitsubishi L300 merupakan kendaraan pengangkutan barang, sehinga muatan beban pada mobil nantinya terdistribusi pada bagian belakang mobil. Muatan mobil maksimal 8 ton. Maka muatan beban untuk masing-masing sisi pada bagian depan menjadi $2000 \mathrm{~kg}$ dengan besar defleksi diasumsikan sebesar 0.1 .

$k_{s}=\frac{\text { Massabeban maksimal } \mathrm{g}}{\delta / 2}$

$k_{s}=\frac{2000 \mathrm{~kg} \times 9.81 \mathrm{~m} / \mathrm{s}^{2}}{0.10 / 2}=392400 \mathrm{~N} / \mathrm{m}$

\section{Koefisien per unsprung (kus)}

Massa quarter-car adalah 291,25 kg dan defleksi mobil diasumsikan 0.1. Konstanta koefisien kus dapat di tentukan dengan perhitungan sebagai berikut :

$k_{u s}=\frac{m_{u s} \times g}{\delta / 2}=\frac{291,25 \mathrm{~kg} \times 9.81 \mathrm{~m} / \mathrm{s}^{2}}{0.10 / 2}$

$k_{u s}=57143,25 \mathrm{~N} / \mathrm{m}$

\section{Koefisien redaman kejut unsprung (Cs)}

Ban yang digunakan adalah ban radial tipe tubless dengan daya tekan ban 34 psi, sehingga kekakuan ban adalah :

$k_{t}=34 \mathrm{psi}=234421.74752 \mathrm{~N} / \mathrm{m}^{2}$

Total massa bagian depan mobil mempengaruhi nilai koefisien redaman unsprung, nilai massa bagian depan mobil dihitung dengan :

$m_{d}=\left(\frac{\text { jarak roda depan }}{\text { jarak sumburoda }}\right) \times\left(\frac{\text { massakosong }}{2}\right)$

$m_{d}=\left(\frac{1440}{2200}\right) \times\left(\frac{1162}{2}\right)=381,27 \mathrm{~kg}$

Konstanta redam kejut unsprung ditentukan dengan :

Nilai kenyamanan redaman adalah :

$\left.c_{\text {us }}^{o p t}\right|_{\text {comfort }} ^{\xi_{c=12 \sqrt{2}}}=\sqrt{2 \times m_{d} x k_{s}}=\sqrt{2 \times 381,27 \times 392400}$

$\left.c_{u s}^{o p t}\right|_{\text {comfort }} ^{\zeta_{c=1 / 2 \sqrt{2}}}=10086,379 \mathrm{~N} / \mathrm{ms}$ $\left.c_{u s}^{o p t}\right|_{\text {comfort }} ^{\zeta_{W=1 / 2}}=\sqrt{\left(k_{s}+k_{t}\right) x m_{u s}}$

$\left.c_{u s}{ }^{o p t}\right|_{\text {comfort }} ^{\zeta_{W=1 / 2}}=\sqrt{(133416+23441,74762) \times 10}$

$\left.c_{\text {us }}{ }^{\text {opt }}\right|_{\text {comfort }} ^{\zeta_{W=1 / 2}}=1252,4286 \mathrm{~N} / \mathrm{ms}$

maka, $c_{s}=(10086,379+1252,4286)=11338,807 \mathrm{~N} / \mathrm{m}^{2}$

Tabel 3. Data sistem suspensi quarter-car

\begin{tabular}{cc}
\hline Parameter & Spesifikasi \\
\hline Massa sprung $\left(\boldsymbol{m}_{\boldsymbol{s}}\right)$ & $281,25 \mathrm{~kg}$ \\
Massa unsprung $\left(\boldsymbol{m}_{u s}\right)$ & $10 \mathrm{~kg}$ \\
Koefisien persprung $\left(\boldsymbol{k}_{s}\right)$ & $392400 \mathrm{~N} / \mathrm{m}$ \\
Koefisien perunsprung $\left(\boldsymbol{k}_{u s}\right)$ & $57143,25 \mathrm{~N} / \mathrm{m}$ \\
Koefisien redaman $\boldsymbol{s p r u n g}$ & $11338,807 \mathrm{~N} / \mathrm{ms}$ \\
$\left(\boldsymbol{c}_{\boldsymbol{s}}\right)$ & \\
\hline
\end{tabular}

2. Hasil perhitungan peredam yang menggunakan magnetorheological sebagai peredam dengan simulink Matlab.

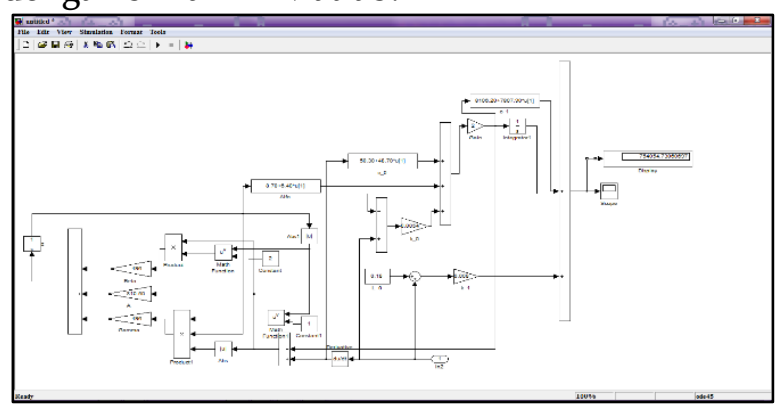

Gambar 5. Hasil perhitungan dengan simulink Matlab

Berdasarkan simulink yang telah dibuat, nilai redaman baru untuk peredam yang menggunakan magnetorheological didapat hasil $7.540 .547,73 \mathrm{~N} / \mathrm{ms}$.

3. Grafik sistem suspensi yang tidak menggunakan magnetorheological sebagai peredam.

a. Grafik posisi

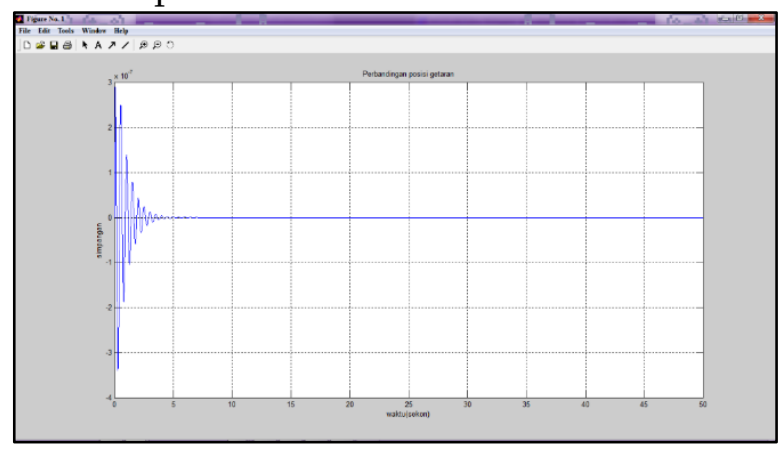

Gambar 6. Grafik posisi 
b. Grafik kecepatan

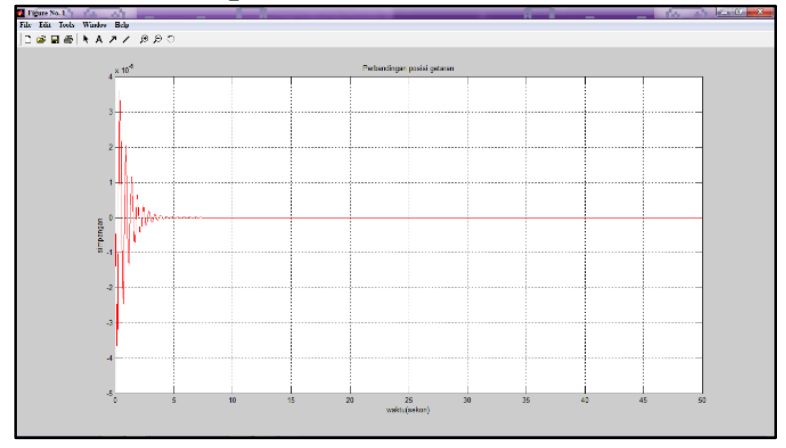

Gambar 7. Grafik kecepatan

c. Grafik percepatan

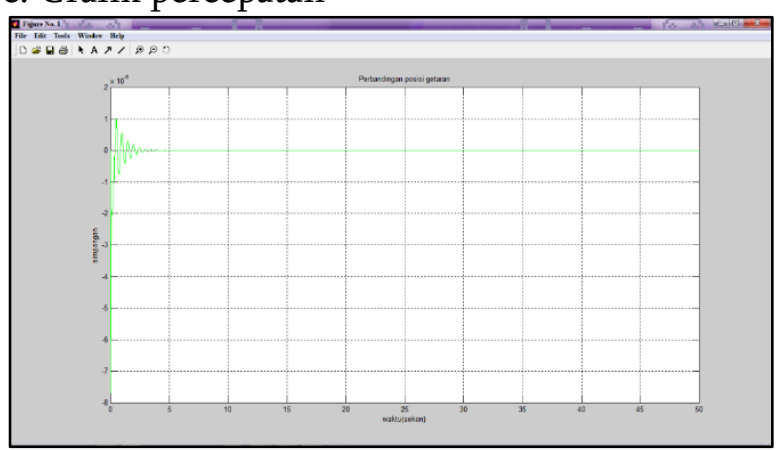

Gambar 8. Grafik percepatan

4. Grafik sistem suspensi yang menggunakan magnetorheological sebagai peredam.

a. Grafik posisi

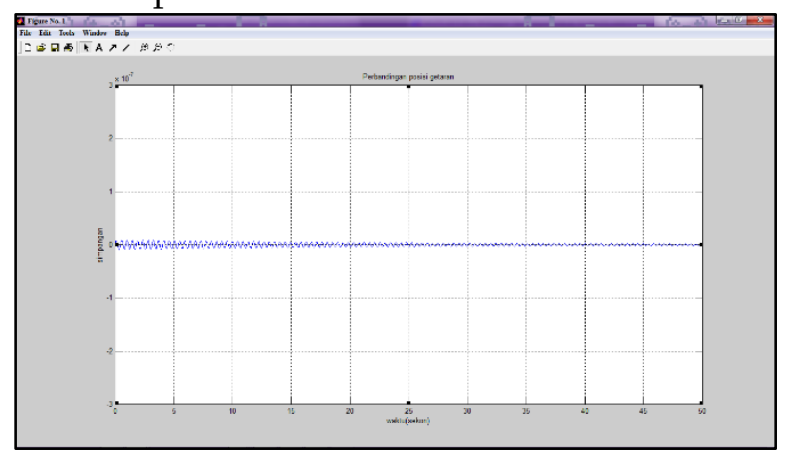

Gambar 9. Grafik posisi

b. Grafik kecepatan

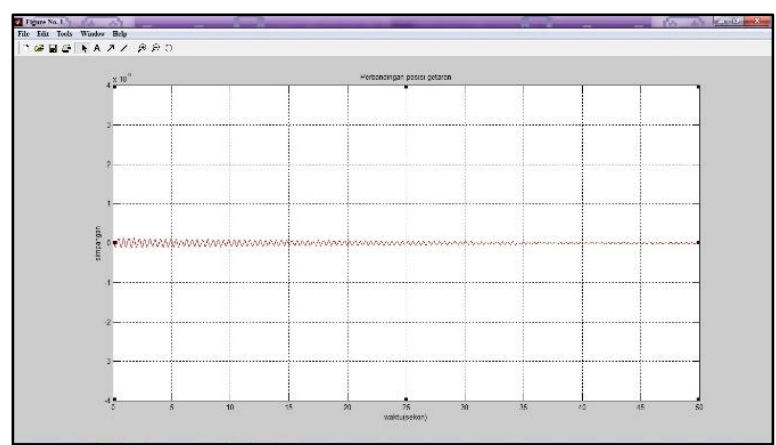

Gambar 10. Grafik kecepatan

c. Grafik percepatan

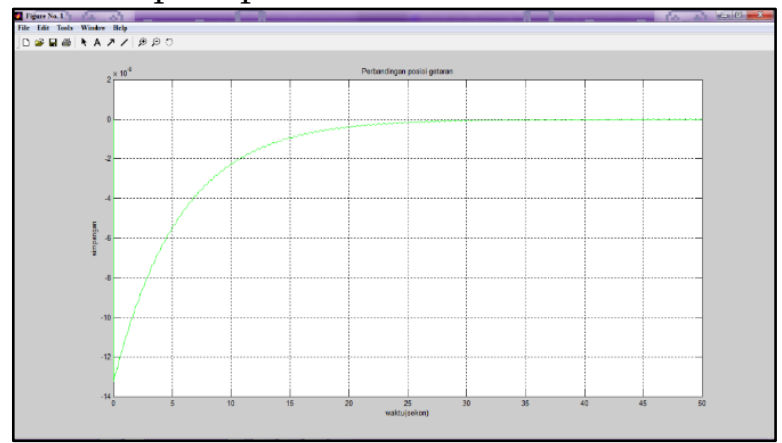

Gambar 11. Grafik percepatan

5. Perbandingan grafik sistem suspensi yang menggunakan dan yang tidak menggunakan magnetorheological sebagai peredam.

\section{a. Grafik posisi}

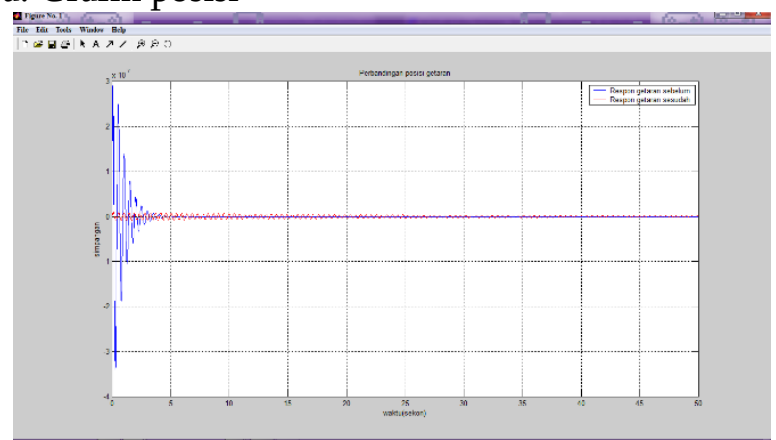

Gambar 12. Perbandingan grafik posisi b. Grafik kecepatan

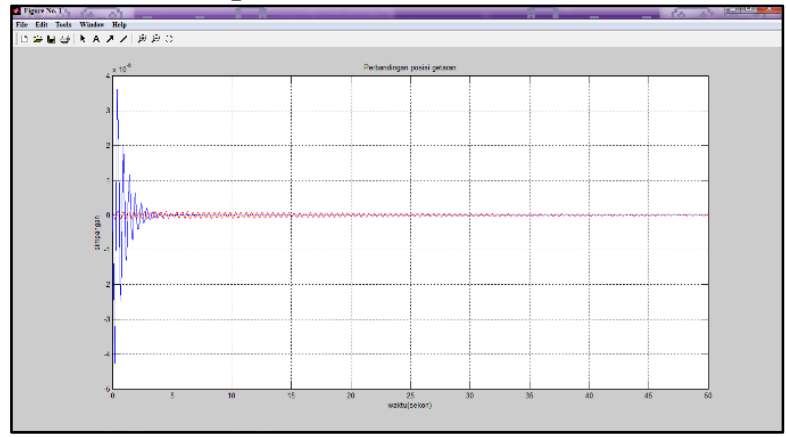

Gambar 13. Perbandingan grafik kecepatan

c. Grafik percepatan 


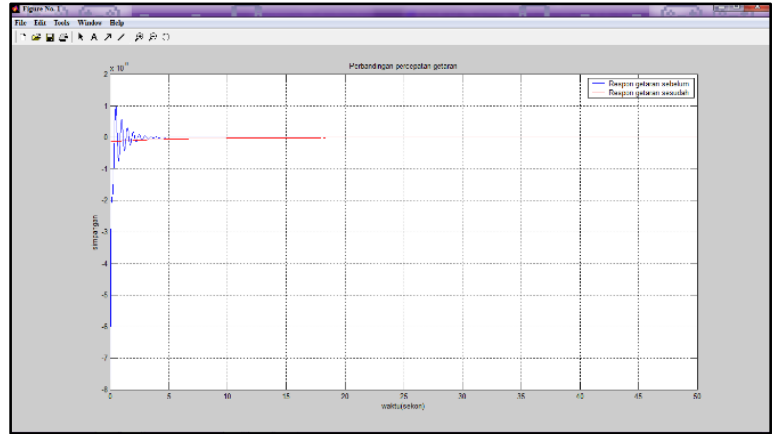

Gambar 14. Perbandingan grafik percepatan

\section{Pembahasan}

a. Pembahasan perbandingan sistem suspensi quarter-car tanpa menggunakan magnetorheological sebagai peredam dan sistem suspensi yang menggunakan magnetor-heological sebagai peredam.

Pembuatan model matematika sistem quarter-car suspensi dalam simulink matlab telah berhasil dilakukan. Simulasi yang dilakukan dalam selang waktu 50 detik dan iterasi 0.05 detik, dikarenakan dalam penetapan waktu tersebut, respon keluaran sistem dapat terdata dengan baik.

Hasil respon keluaran untuk sistem suspensi yang tidak menggunakan magnetorheological sebagai peredam terlihat pada gambar 6,7 dan 8. Sedangkan hasil respon keluaran untuk sistem suspensi yang menggunakan magnetorheological sebagai pere-dam terlihat pada gambar 9,10 dan 11 .

Pada dilihat lebih jelas pada gambar 12,13 dan 14 yang menunjukkan perban-dingan respon getaran vertikal posisi, kecepatan vertikal kendaraan, dan percepatan vertikal kendaraan yang menggunakan magnetorheological sebagai redaman dan yang tidak menggunakan magnetorheological sebagai peredam. Faktor kenyaman dianalisis berdasarkan respon percepatan badan kendaraan.

Pada gambar 12, terlihat bahwa respon getaran sistem suspensi yang menggunakan magnetorheological sebagai peredam lebih kecil dibandingkan sistem suspensi yang tidak menggunakan magnetorheological sebagai peredam. Dimana sistem suspensi yang tidak menggunakan magnetorheological sebagai peredam memiliki goncangan atau getaran yang terlihat sangat jelas pada 0-5 detik pertama.

Pada gambar 13, terlihat bahwa respon kecepatan getaran pada sistem suspensi yang tidak menggunakan magnetorheological sebagai peredam terlihat memiliki kecepatan getaran yang sangat jelas pada 5 detik pertama sebelum akhirnya stabil atau berhenti. Sedangkan kecepatan pada sistem suspensi yang menggunakan magnetorheological sebagai peredam menghasilkan kurva grafik dengan besar simpangan getaran yang jauh lebih kecil dibandingkan sistem suspensi yang tidak menggunakan magnetorheological sebagai peredam. Respon kecepatan getaran sistem suspensi yang menggunakan magnetorheological sebagai peredam memiliki grafik getaran yang lebih stabil.

Pada gambar 14, terlihat bahwa respon percepatan getaran sistem suspensi yang menggunakan magnetorheological sebagai peredam sangat kecil jika dibandingkan respon getaran sistem suspensi yang tidak menggunakan magnetorheological sebagai peredam. Pada respon getaran sistem suspensi yang tidak menggunakan magnetor-heological sebagai peredam terlihat adanya getaran yang sangat jelas pada waktu 0-5 detik.

b. Analisis kenyamanan dan keamanan berdasarkan ISO 2631

Analisisi kenyamanan dan keamanan dilakukan dengan melakuakan pengolaha data dari output data kurva grafik percepatan. Hasil output data dari simulasi terdapat 5.000 data dengan iterasi 0,05 detik pada masing-masing percepatan sebelum dan sesudah menggunakan magnetorheological sebagai peredam. Data tersebut disimpan dan dibuka dengan menggunakan aplikasi pengolahan data microsoft excel. Masing-masing data yang telah disimpan pada Ms. Excel diinput dengan menggunakan persamaan (1) dan (2).

Hasil yang didapat berdasarkan perhitungan VDV dan percepatan RMS pada sistem suspensi yang tidak menggunakan magnetorheological sebagai peredam adalah $0,561 \mathrm{~m} / \mathrm{s}^{1.75}$ dan $0,315 \mathrm{~m} / \mathrm{s}^{2}$. Sedangkan hasil yang didapat berdasarkan perhitungan VDV dan percepatan RMS pada sistem suspensi yang 
menggunakan magnetorheo-logical sebagai peredam adalah $1,568 \mathrm{~m} / \mathrm{s}^{1.75}$ dan $2,456 \mathrm{~m} / \mathrm{s}^{2}$.

\section{KESIMPULAN DAN SARAN}

Dari hasil penelitian, dapat disimpulkan bahwa:

1. Berdasarkan perhitungan suspensi mobil pick-up L300 quarter-car secara simulink didapat nilai kekakuan pegas mobil yang menggunakan peredam magnetorheological sebesar 7.540.547,73 $\mathrm{N} / \mathrm{ms}$ dan telah sesuai dengan standart yang berlaku.

2. Berdasarkan penelitain yang telah dilakukan, bentuk program simulasinya menggunakan program simulink dan program $m$-file pada MATLAB.

3. Berdasarkan hasil penelitian yang telah dilakukan, bentuk grafik dengan iterasi waktu 0,05 detik dan grafik yang terbentuk berupa gelombang sinusoidal yang teredam.

4. Berdasarkan hasil simulasi yang dilakakukan, analisis redaman suspensi mobil yang menggunakan peredam magnetorheological memiliki nilai percepatan RMS dan VDV yang lebih kecil dari pada redaman suspensi mobil yang tidak menggunakan magnetorheological sebagai peredam, dengan nilai percepatan RMS $0,315 \mathrm{~m} / \mathrm{s}^{2}$ dan nilai VDV $0,561 \mathrm{~m} / \mathrm{s}^{1.75}$, sedangkan nilai percepatan RMS suspensi mobil yang tidak menggunakan magnetor-heological sebagai peredam adalah $2,456 \mathrm{~m} / \mathrm{s}^{2}$ dan nilai VDV-nya adalah $1,568 \mathrm{~m} / \mathrm{s}^{1.75}$. Hasil yang didapat telah sesuai dengan standart yang berlaku.

\section{DAFTAR PUSTAKA}

Anggoro, A., (2013), Aplikasi Fuzzy Logic Control Pada Sistem Suspensi SemiAktif Model Kendaraan Seperempat, Skripsi, Semarang: UNDIP.

Talatahari, S., Kaveh, A., Rahbari, N. Mohajer., (2012), Parameter Identification Of Bouc-Wen Model For MR Fluid Dampers Using Adaptive Charged System Search Optimization, Journal of
Mechanical Science and Technology, 26 (8) : 2523-2534.

Gadekar, P., Kanthale, V.S. dan Khaire, N.D., (2017), Magnetorheological Fluid and its Applications, International Journal of Current Engineering and Technology.

Aoki, M., (1987), State Space Modeling of Time Series, Springer-Verlag Berlin Heidelberg, USA.

International Standard ISO 2631-1, Second edition, 1997-05-01, Amendment 1 2010-07-01. 